\title{
Injury prevention in sport: not yet part of the game?
}

\section{J Chalmers}

See end of article for author's affiliation

......................

Correspondence to: Dr D J Chalmers, Injury

Prevention Research Unit, Department of Preventive and Social Medicine,

Dunedin School of

Medicine, University of

Otago, PO Box 913,

Dunedin, New Zealand;

david.chalmers@

ipru.otago.ac.nz art of the game". In other words, injury in Background: There is a sayin
sport is seen as inevitable.

Objective: To examine progress toward reaching the contrary position that "injury prevention is just part of the game".

Methods: The four steps of van Mechelen's "sequence of prevention" model provide a structure for examining progress.

Results: What is known about the size of the problem (step 1)? Most is known about more serious injuries and about injuries in élite and professional sport. Least is known about less serious injuries, injury in community level and amateur sport, and injury occurring in recreational activities. What is known about risk factors (step 2)? Despite calls for analytic studies since the early 1980s, few such studies have been reported in the literature. What is known about the effectiveness of preventive measures (step 3)? Few randomized controlled trials have been reported in the literature. Are there systems in place to monitor sports injury (step 4)? Examples are given of systems in North America, Europe, and Australasia.

Conclusions: With a few exceptions, progress has not gone beyond step 1 in van Mechelen's model. Challenges for the future include: deciding where research efforts should be placed, standardization of definitions and methods of data collection and reporting, identification of risk factors and mechanisms of injury, and the evaluation of interventions. Finally, if the field of sports injury prevention is to advance, multidisciplinary collaboration will be required, along with the involvement of the sports community.
$\mathrm{T}$ here is a saying in sport that "injury is just part of the game". In other words, injury is seen as an inevitable consequence of participation in sport. As sports injury prevention researchers and practitioners we hold a contrary view. We argue that sports injuries can be prevented and need not be part of the game. Ideally, we would like to reach the position where it is said that "injury prevention is just part of the game".

This paper examines how far we have progressed toward reaching this position and will identify some challenges for the future. The paper is structured around Willem van Mechelen's familiar "sequence of prevention" model. ${ }^{1}$ There are four steps to the model:

(1) Establishing the extent of the sports injury problem.

(2) Establishing the etiology and mechanism of sports injury.

(3) Introducing preventive measures.

(4) Assessing the effectiveness of these preventive measures by repeating step 1 .

\section{DEFINITIONS}

Before examining our progress, I shall discuss some issues relating to definitions of sport, sports injury, and sports injury prevention. These are not new issues. They were raised at the 3rd World Conference on Injury Prevention and Control in Melbourne, Australia, in 1996. No real progress has been made toward their resolution.

\section{Sport}

Many definitions of "sport" are offered in the literature. Many of these are circular, such as this one from the Australian Sports Commission: "a human activity capable of achieving a result requiring physical exertion and/or physical skill which by its very nature and organisation is competitive and is generally accepted as being sport". ${ }^{2}$
Recently, while seeking a definition that would incorporate both organized sport and informal physical recreation, I resorted to the Concise Oxford Dictionary and came up with the following: "any pastime or game requiring physical effort that is undertaken for amusement, diversion or fun". ${ }^{3}$ Such activity can be competitive or recreational, amateur or professional. Incidentally, the word sport is actually a corruption of "disport", which is defined as: "1. Frolic, gambol, enjoy oneself, display oneself sportively (playfully). 2. Relaxation, pastime". ${ }^{3}$

\section{Sports injury}

There are also many definitions of "sports injury" in the literature. These are generally operational definitions developed for a particular study and are couched in terms of inclusion criteria, such as "inability to continue participation" or "requiring medical treatment". Often, some level of severity is implied in these definitions, such as the amount of time lost from participation or the level of treatment provided, be it first aid, emergency care, or hospital admission.

A definition of injury commonly used in the wider field of injury prevention and control is "any unintentional or intentional damage to the body ... caused by acute exposure to physical agents such as mechanical energy, heat, electricity, chemicals, and ionizing radiation interacting with the body in amounts or at rates that exceed the threshold of human tolerance" ${ }^{\prime 4}{ }^{5}$

If we take this as our starting point and add "participation in sport" then I suggest we have an acceptable definition for sports injury. In brief, this would read as: "any unintentional or intentional damage to the body resulting from participation in any pastime or game requiring physical effort that is undertaken for amusement, diversion, or fun". I should acknowledge that Ronald LaPorte and colleagues presented a similar argument and definition in a paper on the surveillance of recreational injuries, published in $1993 .^{6}$ 
The real problem lies in how we operationalize this, or any other, definition of sports injury. Unfortunately, we seem to do this in a bewildering variety of ways. In an article on athletic injury reporting published in 1997, Willem Meeuwisse and Edgar Love suggested that we employ a "flexible" definition of injury at the data collection phase of a study and then refine this at the analysis stage. ${ }^{7}$ This would involve using broad inclusion criteria and then collecting sufficient additional information, such as time lost due to injury, to permit various definitions of injury to be applied. This will not be practicable in some situations but may offer a way forward.

\section{Sports injury prevention}

Finally, what is this field we call "sports injury prevention"? Caroline Finch, in an address to the 5th World Conference on Injury Prevention and Control in New Delhi, in 2000, suggested that the sports injury domain has traditionally been governed by advances in sports medicine. She argued, however, that there had been a paradigm shift which has seen:

(1) Increasing recognition given to sports injuries as a significant public health issue.

(2) The need for a strong preventive approach.

(3) The emergence of sports injury epidemiology as a subdiscipline.

(4) Considerable effort targeting surveillance activities.

This places us squarely in the public health arena, with an emphasis on "epidemiology" and "health promotion". I will come back to this issue later, as I believe that our field must be defined more widely than this.

\section{WHAT DO WE KNOW ABOUT THE SIZE OF THE PROBLEM (STEP 1)?}

We know most about the more serious injuries-deaths, hospital admissions, and emergency department presentationsand about injuries at the élite and professional levels of sport. We know least about less serious injuries-as treated in sports medicine clinics or by general practitioners, injury at the community or amateur levels of sport, and injury occurring in recreational activities (for example, swimming, hiking). Some attempts have been made to redress this imbalance, including the national survey of injuries in sport and exercise conducted in England and Wales by Nicholl and colleagues in 1989/1990, and the study of sport and recreational injury in the LaTrobe Valley, Victoria, Australia, conducted by Finch and colleagues in 1994/1995. ${ }^{.9}$

We also know most about numbers of injuries and least about rates of injury. In their article on athletic injury reporting, Meeuwisse and Love $^{7}$ described three types of injury reporting systems:

(1) Case series designs: these may be injury specific, sport specific or population based, use hospital records or some other convenient source of cases, are open to bias, and cannot generally provide rates.

(2) Cohort designs with exposure estimation: in these, exposure is measured as the number of games or practices in which the population participated over a given period, and rates can be provided.

(3) Cohort designs with exposure measurement: in these designs the time spent in participation by each individual is recorded, and rates can be provided.

Most reported studies fall into the first of these categories and least into the final category.

\section{What level of injury should we be interested in?}

This depends on our perspective: be it that of public health practitioners, national sports organizations, or individual sports people. From a "public health" perspective we might be interested in the most common injuries, the most severe, the most debilitating, or the most costly. Or we might be interested in what prevents people from being physically active. It is now well established that there are substantial health benefits to be gained from regular physical activity, especially in regard to cardiovascular disease, diabetes, some cancers, osteoporosis, and psychological wellbeing. ${ }^{10}$ In many countries, regular physical activity is being promoted as a public health priority. ${ }^{11}$ This raises a number of questions for sports injury prevention:

(1) What impact will an increasingly active population have on the incidence of injury? I don't know of any research that has investigated this relationship directly.

(2) What sporting and recreational activities can provide the prescribed levels of physical activity while minimizing the risk of injury? Risk analyst, David Ball, warns that "careful consideration needs to be afforded to the type of activities recommended for various age groups, and that advice should be given on risks". ${ }^{12}$

(3) What impact does injury have on participation in physical activity? Caroline Finch and her colleagues have shown that in a representative sample of Australian urban adults, 54\% identified current injury or disability as a barrier to increased physical activity. ${ }^{13}$

From the perspective of a "national sports organization" our primary interest might be in what prevents élite or highly paid professional athletes from performing regularly and earning revenue for their sport. We might also be interested in the most severe and debilitating injuries; those that discourage people from participating in the sport, or attracting costly litigation.

From the perspective of the "individual sports person" we might be interested in those injuries that are the greatest barriers to personal achievement. This may range from participating on a regular basis, to advancement to the élite or professional ranks of a sport. As some writers have argued, an injury that might be considered minor from a public health perspective, such as a strain or a sprain, may be catastrophic for an athlete about to compete in a national or international event. ${ }^{14}$ Similarly, overuse injuries, which develop gradually over time, may not appear in hospital records but may prevent or limit participation for significant periods of time. ${ }^{15}$

While it is tempting to suggest that we concentrate our efforts on the most serious injuries, those resulting in death or hospitalization, I don't believe that we can ignore the problem of less serious injury that prevents or limits participation in sporting activity. One of the challenges we face is in determining just how great this problem is.

\section{What are the barriers to describing the incidence of sports injury?}

The application of descriptive epidemiologic methods to sports injury has been well described in a number of publications. ${ }^{16716-18}$ There are also some good examples of the application of these methods. The greatest challenge, as I see it, lies in the collection of exposure data. There are three key aspects to this:

(1) Defining the population of interest. For organized sport this is less of a problem, but for informal, recreational activities this may be extremely difficult. How, for example, do we define the population of people undertaking physical activity to improve their general health? Do we only include those who do this outside of organized sport? That would exclude those who choose to increase their physical activity by taking up organized sport!

(2) Gaining access to the population of interest. In New Zealand we are attempting to develop a national injury surveillance system for a major sport. Surprisingly, it does not have a complete, accurate, and up to date register of its players. It 
is very difficult, therefore, to obtain access to a representative sample of players.

(3) Obtaining reliable measures of person-time exposure. While it may be possible for very accurate records to be kept of individual exposure at élite and professional levels of sport, where there are few participants and substantial resources, this is less the case for community level or amateur sports, or for informal recreational activity.

\section{WHAT DO WE KNOW ABOUT RISK FACTORS FOR SPORTS INJURY (STEP 2)?}

There have been calls in the literature for analytic, or risk factor, studies since the early 1980 s. $^{18-20}$ To date, however, few such studies have been reported in the international literature. ${ }^{21}$ It is of historic interest to note that William Haddon, the founding father of injury prevention research, published a case-control study of risk factor for skiing injuries in 1962. Haddon and his colleagues found "a significant association between the occurrence of injury and the use of non-release bindings among males". ${ }^{22}$

One risk factor about which there is some agreement is that of "previous injury". Several studies have shown that the risk of injury is elevated for sports people who have a previous injury. ${ }^{23-30}$ Odds ratios ranging from 1.6 to 9.4 have been reported. While it is important to know this, the real challenge is to prevent the first occurrence of injury and for this we need to know about the risk factors involved.

\section{Why are there so few analytic studies?}

First, there are the general reasons that apply to the wider field of injury prevention and control: the field is young, the research community is small, and the cost of analytic studies is high. Beyond these general reasons, there are practical difficulties in undertaking analytic studies in this area. For example:

(1) The incidence of injury in most sports is quite low, especially for specific injury types and/or severe injuries. This rules out cohort studies in many sports.

(2) We may lack adequate or appropriate measures of potential risk factors. In our study of rugby injury we found no significant associations between physical performance measures and injury, despite the widespread belief that physical fitness protects against injury. It may be that our measures did not adequately assess the type or level of fitness required for rugby. ${ }^{28}$

\section{WHAT DO WE KNOW ABOUT THE EFFECTIVENESS OF PREVENTIVE MEASURES (STEP 3)?}

Steps 3 and 4 of van Mechelen's model involve the introduction of preventive measures (step 3) and the evaluation of their effectiveness through the repetition of step I (step 4). van Mechelen, in his 1997 paper, acknowledges that there is another step in this process. ${ }^{15}$ Before introducing preventive measures and monitoring subsequent injury incidence the effectiveness of the measures should be evaluated, ideally by undertaking "randomized controlled trials".

As for risk factor studies, few randomized controlled trials of preventive measures for sports injury have been reported in the international literature. ${ }^{31}$ In fact there is very little evidence at all of the effectiveness of preventive measures for sports injury. At this point I would like to pay tribute to the efforts of Caroline Finch, Joan Ozanne Smith, and their Australian colleagues in reviewing the literature on "countermeasures for sports injury". In this massive undertaking they have provided an invaluable resource with comprehensive reviews on over 20 sports. ${ }^{32-37}$ I should also acknowledge the recent work done in Canada by Morag MacKay and her colleagues on reviewing the literature on preventive strategies. ${ }^{38}$
Why are there so few randomized controlled trials? The reasons why few randomized controlled trials have been conducted are similar to those for risk factor studies. There are, however, some additional practical difficulties. For example, it is difficult to evaluate preventive measures when they are already widely practised in a sport. van Mechelen et al found this in their trial of warm-up, cool-down, and stretching exercises in runners. Ninety percent of their subjects already performed some form of warm-up and cool-down procedures. ${ }^{39}$ Sports people and organizations are keen to find solutions to problems and once they learn of a good idea they are reluctant to wait several years for a randomized controlled trial to be undertaken.

\section{DO WE HAVE SYSTEMS IN PLACE TO MONITOR SPORTS INJURY (STEP 4)?}

With this fourth step, we return to step 1 and complete the loop in van Mechelen's model. Do we have any systems for the routine monitoring of sports injuries? In their 1997 paper on athletic injury reporting, Meeuwisse and Love ${ }^{7}$ provided a comprehensive review of reporting systems in North America. Among those identified were the Sport Injury Monitoring System (SIMS) in the United States and the Canadian Intercollegiate Sport Injury Registry (CISIR), to name but two, and in the European Union nations, the European Home and Leisure Accident Surveillance System (EHLASS). In New Zealand, several national agencies monitor serious sports injury-mainly fatalities-occurring in aviation, boating, and in mountain sports, including skiing, hiking, and hunting. Two government agencies, the Accident Compensation Corporation and the New Zealand Health Information Service, collect data on more serious injury, from which sports injuries can be abstracted to varying degrees. A recent survey of national sports organizations found that 20 had some form of data collection, but most concentrated on serious injuries and élite players (D Chalmers and P Gulliver. Sports injury surveillance in New Zealand: Report to the Accident Compensation Corporation, 2001).

\section{CONCLUSION}

If we go back to the question posed in the title, we must conclude that injury prevention is "not yet part of the game" for most sports. With a few exceptions, we have not progressed beyond step 1 in van Mechelen's model. Before finishing, I want to consider some challenges for the future.

Earlier I quoted a widely used definition of injury. In short this read: "any damage to the body ... caused by acute exposure to physical agents ... in amounts or at rates that exceed the threshold of human tolerance". If we think now about the nature of sport, this is an aspect of life in which individuals deliberately push their bodies to the threshold of human tolerance. This endeavor is embodied in the motto of the Olympic Games, the most important sporting event on earth: "Citius, Altius, Fortius" or "Swifter, Higher, Stronger". ${ }^{40}$

In what other aspects of life do we do this? In what other aspects of life do we do so with a minimum of protection against injury? Is it surprising then that injury is seen as being just part of the game? Should we just accept this and leave it to our colleagues in sports medicine to treat the injured as they fall? Is there any real hope of achieving our goal of making injury prevention part of the game?

\section{Challenges for the future}

Assuming that we are not going to give up without a fight, what should we be doing? I have several suggestions:

(1) We need to decide where we are going to place our efforts. Earlier I suggested that we had a choice between the most serious injuries or those that have the greatest impact on 
participation and the aspirations of sports people. That is one choice. Another choice is between specific sports and specific injuries that are common across sports, such as ankle sprains.

(2) If we are to gain any real understanding of the size of the problem within sports, between sports, or between countries, we need to strive for standardization in our definitions and in our methods of data collection and reporting. More importantly, we need to move on to step 2 and identify risk factors and mechanisms of injury.

(3) We need to think about our prevention options. Should we be concerned about preventive measures already in place, many of which may have evolved over many years along with the evolution of sport? Should we be concerned with trying to determine if they work or not? Whether or not they work may be immaterial, because sports people, being superstitious folks, may be reluctant to abandon them, even if they don't work! Shouldn't we be looking for new options or at the very least improving on the old ones? Whatever course we choose, we have to move on to steps 3 and 4 , and evaluate our interventions.

(4) Finally, we need to think about our role in this endeavor. Earlier I suggested that we needed to define our field more widely. Back in 1985, in the publication Injury in America, ${ }^{41}$ five major sectors were identified as having a role in injury prevention: epidemiology, biomechanics, acute care, rehabilitation, and prevention-which I take to mean health promotion. If we are to advance our field, we need to collaborate with our colleagues in all of these disciplines.

There are two omissions from the above list. The first is the behavioral sciences, such as psychology and sociology. I believe that these disciplines have an important role to play in understanding the sports people and sports organizations we hope to influence. The second, and most important, is sport itself. Having the input of the sports that we hope to influence, at all stages of the process of investigating injury, will be crucial to ensuring that injury prevention becomes "just part of the game".

\section{Author's affiliation}

D J Chalmers, Injury Prevention Research Unit, Department of Preventive and Social Medicine, Dunedin School of Medicine, University of Otago, Dunedin, New Zealand

\section{REFERENCES}

1 van Mechelen W, Hlobil H, Kemper HCG. Incidence, severity, aetiology and prevention of sports injuries. Sports Med 1992;14:82-99.

2 Australian Sports Commission. Sport: a great investment. Canberra: Australian Sports Commission, 1993

3 Fowler HW, Fowler FG, eds. The Concise Oxford Dictionary of Current English, 5th edn. London: Oxford University Press, 1964.

4 Baker SP, O'Neill B, Ginsburg M, et al. The injury fact book, 2nd edn. New York: Oxford University Press, 1992.

5 National Committee for Injury Prevention and Control. Injury prevention: meeting the challenge. Am J Prev Med 1989;5(3 suppl).

6 Laporte RE, Kohl HW, Dearwater SR, et al. Surveillance of serious recreational injuries: a capture-recapture approach. Med Sci Sports Exerc 1993;25:204-9.

7 Meeuwisse WH, Love EJ. Athletic injury reporting. Development of universal systems. Sports Med 1997;24:184-204.

8 Nicholl J, Coleman P, Williams B. A national study of the epidemiology of exercise-related injury and illness: injuries in sport and exercise-main report. Sheffield: Medical Care Research Unit, Sheffield University Medical School, 1991.
9 Finch C, Cassell E, Stathakis V. The epidemiology of sport and active recreation injury in the Latrobe Valley. Clayton, Vic: Monash University, 1999.

10 National Health Committee. Active for life: a call for action. Wellington: National Health Committee, 1998.

11 Chalmers DJ. The public health impact of sports injuries. Sport Health 1999;17:14-15.

12 Ball DJ. Looking ahead. Sports Exercise and Injury 1998;4:174-82.

13 Finch CF, Owen N, Price R. Current injury or disability as a barrier to being more physically active. Med Sci Sports Exerc 2001;33:778-82.

14 Finch CF. An overview of some definitional issues for sports injury surveillance. Sports Med 1997;24:157-63.

15 van Mechelen W. The severity of sports injuries. Sports Med 1997;24:176-80.

16 Caine DJ, Caine CG, Lindner KJ. Epidemiology of sports injuries. Champaign, IL: Human Kinetics, 1996.

17 de Loes M. Exposure data: why are they needed? Sports Med 1997;24:172-5.

18 Walter SD, Hart LE. Application of epidemiological methodology to sports and exercise science research. Epidemiological Methodology in Sports and Exercise Science Research 1990;18:417-48.

19 Kraus JF, Conroy C. Mortality and morbidity from injuries in sports and recreation. Annu Rev Public Health 1984;5:163-92.

20 Meeuwisse WH. Predictability of sports injuries: what is the epidemiological evidence? Sports Med 1991;12:8-15

21 Bleakley C, MacAuley D. The quality of research in sports journals. $\mathrm{Br} J$ Sports Med 2002;36:124-5.

22 Haddon W, Ellison AE, Carroll RE. Skiing injuries: epidemiologic study. Public Health Rep 1962;77:973-85.

23 Dryden DM, Francescutti LH, Rowe BH, et al. Personal risk factors associated with injury among female recreational ice hockey players. J Sci Med Sport 2000;3:140-9.

24 Emery CA, Meeuwisse WH. Risk factors for groin injuries in hockey. Med Sci Sports Exerc 2001;33:1423-33.

25 Greene HS, Cholewicki J, Galloway MT, et al. A history of low back injury is a risk factor for recurrent back injuries in varsity athletes. Am J Sports Med 2001;29:795-800.

26 Hootman JM, Macera CA, Ainsworth BE, et al. Predictors of lower extremity injury among recreationally active adults. Clin J Sports Med 2002;12:99-106.

27 Lee AJ, Garraway WM, Arneil DW. Influence of preseason training, fitness, and existing injury on subsequent rugby injury. Br J Sports Med 2001;35:412-17.

28 Quarrie KL, Alsop JC, Waller AE, et al. The New Zealand rugby injury and performance project. VI. A prospective cohort study of risk factors for injury in rugby union football. Br J Sports Med 2001;35:157-66.

29 Van Mechelen W, Twisk J, Molendijk A, et al. Subject-related risk factors for sports injuries: a 1-yr prospective study in young adults. Med Sci Sports Exerc 1996;28:1171-9.

30 Watson AW. Sports injuries related to flexibility, posture, acceleration, clinical defects, and previous injury, in high-level players of contact sports. Int J Sports Med 2001;22:222-5.

31 Parkkari J, Kujala UM, Kannus P. Is it possible to prevent sports injuries? Review of controlled clinical trials and recommendations for future work. Sports Med 2001;31:985-95

32 Clavisi O, Finch CF. Striking out squash injuries-what is the evidence? International Journal for Consumer \& Product Safety 1999:6:145-57.

33 Clavisi O, Finch CF. Squash injury countermeasures: a review of the literature. J Sci Med Sport 2000;3:13-22.

34 Daley RM, Bass SL, Finch CF. Balancing the risk of injury to gymnasts: how effective are the counter measures? Br J Sports Med 2001;35:8-20.

35 Finch CF, Elliott BC, McGrath AC. Measures to prevent cricket injuries: an overview. Sports Med 1999;28:263-72.

36 Gabbe B, Finch CF. Injury countermeasures in Australian Football. J Sci Med Sport 2000;3:31-40.

37 Sherman CA, Finch CF. Preventing injuries to competitive and recreational adult golfers: What is the evidence? J Sci Med Sport 2000;3:65-78

38 MacKay M, Scanlan A, Olsen L, et al. Sports and recreation injury prevention strategies: systematic review and best practices: executive summary. Vancouver, BC: BC Injury Research and Prevention Unit, 2001

39 van Mechelen W, Hlobil H, Kemper HCG, et al. Prevention of running injuries by warm-up, cool-down, and stretching exercises. Am J Sports Med 1993;21:711-19.

40 Berlioux M. The history of the International Olympic Committee. In: Killanin MM, Rodda J, eds. The Olympic Games 1984. London: Willow Books, 1983

41 Committee on Trauma Research, Commission on Life Sciences, National Research Council, et al. Injury in America: a continuing public health problem. Washington: National Academy Press, 1985. 